\title{
Live VM Migration: An Algorithmic Implementation Approach
}

\author{
Santosh Kumar Majhi \\ Dept. of Computer Sc \& Engg \\ VSS University of Technology \\ Burla, India
}

\author{
Suresh Kumar \\ Srichandan \\ Dept. of Computer Sc \& Engg \\ VSS University of Technology \\ Burla, India
}

\author{
Sunil Kumar Dhal \\ Faculty of Research and \\ Doctoral Studies \\ Sri Sri Universty, Cuttack, India
}

At the request of the editorial board of Communications on Applied Electronics via memo 2019/362G, this article is hereby removed from the journal and its affiliated academic indexes. The article has been found to have infringed the copyrights of a book: "Mobile Cloud Computing: Principles and Paradigms, 1/e, ISBN: 9789384588915, Abhirup Khanna \& Sarishma". 